\title{
Environmental Impact Assessment of Petrochemical Industry using Fuzzy Rapid Impact Assessment Matrix
}

\author{
Morteza Ghobadi ${ }^{*}$, Hamid Reza Jafari ${ }^{1}$, Gholam Reza Nabi Bidhendi² and Ahmad Reza Yavari ${ }^{1}$ \\ ${ }^{1}$ Department of Environmental Planning, Tehran University, Tehran, Iran \\ ${ }^{2}$ Environmental Engineering, Tehran University, Tehran, Iran
}

\begin{abstract}
Due to the high potential of petrochemical industry in the creation of environmental impact, environment impact assessment of the development of petrochemical industry is very important. The aim of this study is to provide and test a fuzzy model for environmental impact assessment of petrochemical industries as a decision support system in planning process and the development of petrochemical industry. To test this model, the Lorestan province was chosen as the study area. In order to assess the impact of petrochemical industry in Lorestan, the combination of RIAM method and fuzzy theory was used. First, using check lists and holding meetings with experts, the type of petrochemical industry impacts on environmental factors was determined. Next, the effects of project activities on environmental factors were scored; the fuzzy scoring was done using defined criteria in MATLAB software. Environmental components considered in the method used were divided into 4 main factors including physicalchemical, biological-ecological, social-cultural and economic-functional and 33 sub-factors, assessment of nonimplementation, construction and operation stage was carried out individually. The results show the most important environmental impacts of petrochemical projects, water and soil pollution, air and noise as well as its socioeconomic consequences. The results showed that the operation in petrochemical industry will create more important implications than the construction stage, some of them in terms of lack of control and environmental management, are irreversible and damaging.
\end{abstract}

Keywords: Environmental impact assessment; RIAM; Fuzzy theory; Petrochemical industry

\section{Introduction}

Economic and industrial activities, coupled with rapid population growth, as well as the lack of interest in the efficient use of natural resources have led to disrupt the ecological balance [1,2]. Inappropriate land use change, pollution, the destruction of natural resources is considered as some serious problems of environmental imbalances around the world $[3,4]$. These problems indicate the fact that the world's natural environment has limited ecological power for human use in some areas, nature with minimal loss provides the highest development, and in others, minimum development and manipulate in it leads to the irreversible effects [5]. Therefore, in order to reduce these impacts, and achieve appropriate land development, especially regional development, there is need to taking advantage of the features and functionality of each part of the country for planning [6,7]. Whatever this plan is based on objective facts and the natural potential, achieving to pre-determined targets will be more feasible. Moreover, if the planning of economic development is done without attention to social, cultural and natural issues, not only will not solve the critical problems, but also makes them worse [8]. An important issue that is considered in this research is that, often regional environmental planning in Iran and many countries is prepared in large areas such as provinces and large areas of the watershed where are facing with the intensity or environmental crisis [9]. On the other hand, the petrochemical industry, as an important source for manufacturing needs of domestic industries has a special potential and place in the national economy [10] and due to the potential of this industry in creation of environmental impacts, environment impact assessment of the development of petrochemical industry is very important [11]. Environmental impact assessment is one of the acceptable methods for achieving the goals of sustainable development, and as a planning tool can identify potential environmental impacts which appear after implementation of petrochemical projects, and select the logical options to eliminate and reduce them $[12,13]$. The most important feature of environmental impact assessment is to predict the adverse, negative and destructive effects of environmental loadings. In this way, stakeholders at different levels of decision-making and executive, find an unparalleled opportunity to familiar with the negative effects of desired loadings timely and take appropriate measures to eliminate, reduce and manage the unintended effects [14]. Prevention of problems always is less costly than dealing with the issues. Now, there is no means for environmental impact assessment in petrochemical industry planning system. Therefore, this study tries to calculate and determine the most important effects of the activities of petrochemical industry on environmental factors for the lack of implementation option and construction and operation in the Lorestan province using the RIAM method as fuzzy, in the form of suitable software design for development impact assessment.

\section{Case Study}

Lorestan Province is about $28157 \mathrm{~km}^{2}$. It is in the west part of Iran between $46^{\circ} 50^{\prime}$ to $50^{\circ} 01^{\prime}$ east longitude and $32^{\circ} 40^{\prime}$ to $34^{\circ} 23^{\prime}$ northern latitude (Figure 1). The average height of Lorestan is $2200 \mathrm{~m}$ from sea level. The lowest part of Lorestan is located in plains, $239 \mathrm{~m}$ and

*Corresponding author: Morteza Ghobadi, Ph.D Student, Department of Environmental Planning, Tehran University, Tehran, Iran, Tel: +98 (21) 66404647; E-mail: ghobadim93@gmail.com

Received August 11, 2015; Accepted August 27, 2015; Published September 7, 2015

Citation: Ghobadi M, Jafari HR, Bidhendi GRN, Yavari AR (2015) Environmental Impact Assessment of Petrochemical Industry using Fuzzy Rapid Impact Assessment Matrix. J Pet Environ Biotechnol 6: 247. doi:10.4172/21577463.1000247

Copyright: (c) 2015 Ghobadi M, et al. This is an open-access article distributed under the terms of the Creative Commons Attribution License, which permits unrestricted use, distribution, and reproduction in any medium, provided the original author and source are credited. 


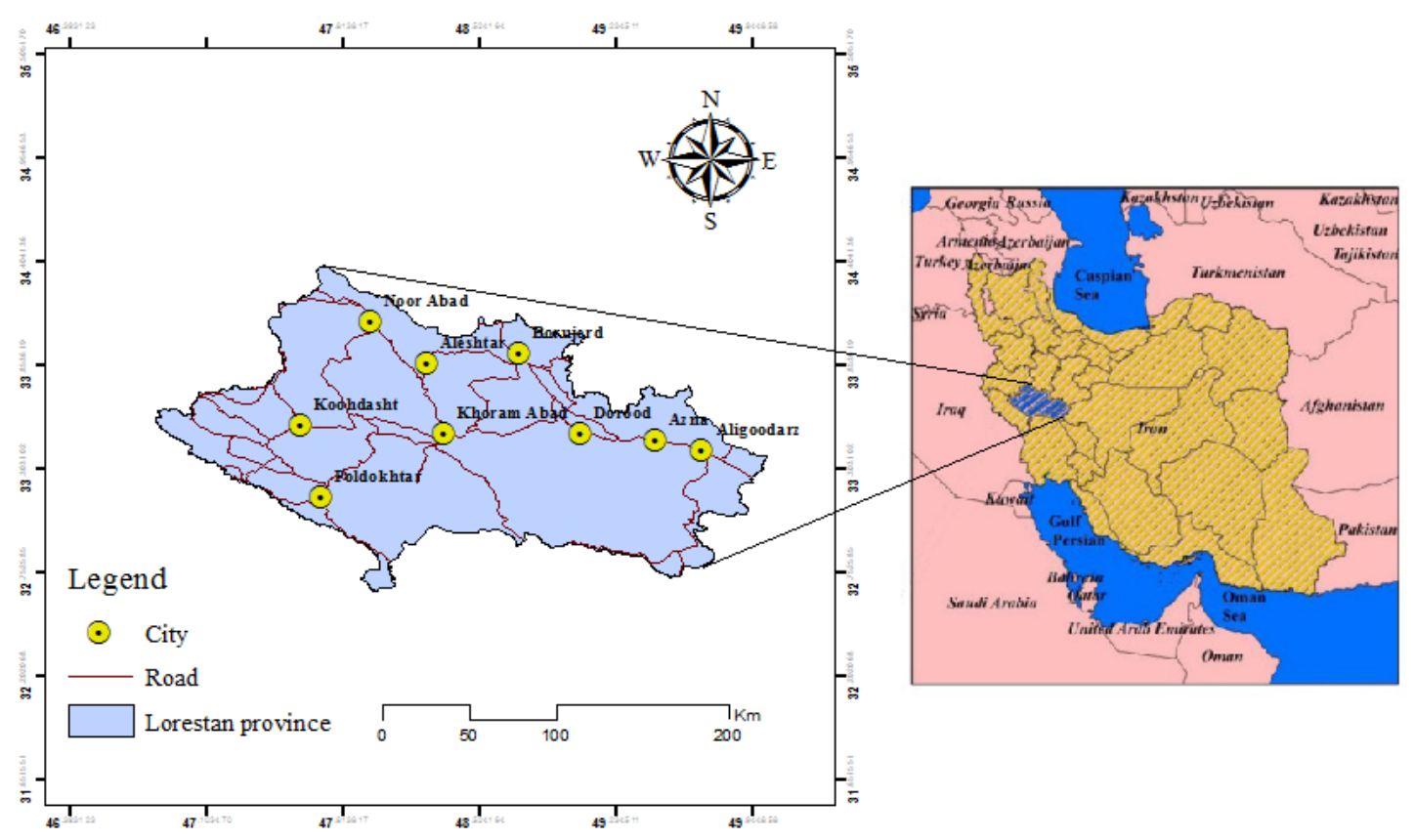

Figure 1: Case study, Lorestan Province.

the highest part of this Province is about $4080 \mathrm{~m}$ Oshtoran Kooh Mountains in Zagros Mountains. This province covers about $1.72 \%$ of total area of Iran by ranking $16^{\text {th }}$ among provinces. Lorestan Province is limited from north by Hamedan Province, from northeast by Markazi Province; from east by Esfahan Province, from southeast by Chahar Mahal va Bakhtiari, from south by Khuzestan Province, from west by Ilam Province and from northwest side by Kermanshah Province.

\section{Method}

\section{Fuzzy ranking method}

In this method to compare two triangular fuzzy numbers of $\widetilde{A}$ (a,b,c) and $\widetilde{B}$ (d,e,f) we change them to two crisp numbers and then we compare them. The important issue is how to change a fuzzy number to a crisp one with saving the characteristics. In the following the novel method is presented.

In this method three possible modes of a triangular fuzzy number are considered which their presented in the following [14-16].

i) Triangular with no vertical side $(a \neq b \neq c)$

First, five vertical $\alpha$-cuts with equal distances are drawn between a and $\mathrm{b}$ (Figure 2).

$$
x h_{i}=a+i\left(\frac{b-a}{6}\right) \text { and } \mathrm{i}=1,2,3,4 \text { and } 5
$$

Second, the places of each $\alpha$-cuts to deal with the side ab are calculated.

$$
y h_{i}=\left(\frac{1}{b-a}\right) *\left(x h_{i}-a\right) \text { and } \mathrm{i}=1,2,3,4 \text { and } 5
$$

This work is also would be done for side bc.

$$
\begin{aligned}
& x h_{i}=a+i\left(\frac{c-b}{6}\right) \text { and } \mathrm{i}=6,7,8,9 \text { and } 10 \\
& y h_{i}=\left(\frac{-1}{c-b}\right)^{*}\left(x h_{i}-b\right)+1 \text { and } \mathrm{i}=6,7,8,9 \text { and } 10
\end{aligned}
$$

And also, $x h_{11}=b$ and $y h_{11}=1$ are assumed. Finally, the equivalent weight of the triangular fuzzy number of $\widetilde{A}$ is

$W_{\tilde{A}}=\sum_{i=1}^{10}\left(x h_{i}^{*} y h_{i}^{0.01}\right)+b$

ii) Triangular with a vertical side $(a=b, b \prec c)$

First, ten vertical $\alpha$-cuts with equal distances are drawn between a and c (Figure 3).

$$
x h_{i}=a+i\left(\frac{c-a}{11}\right) \text { and } \mathrm{i}=1,2,3, \ldots 10
$$

Second, the places of each $\alpha$-cuts to deal with the side bc are calculated.

$$
y h_{i}=\left(\frac{-1}{c-b}\right) *\left(x h_{i}-b\right)+1 \text { And } \mathrm{i}=1,2,3,10
$$

And also, $x h_{11}=a$ and $y h_{11}=1$ are assumed. Finally, the equivalent weight of the triangular fuzzy number of $\widetilde{A}$ is

$$
W_{\tilde{A}}=\sum_{i=1}^{10}\left(x h_{i}^{*} y h_{i}^{0.01}\right)+a
$$

iii) Triangular with a vertical side ( $b=c, a \prec b$ )

First, ten vertical $\alpha$-cuts with equal distances are drawn between a and c (Figure 4).

$$
x h_{i}=a+i\left(\frac{c-a}{11}\right) \text { and } \mathrm{i}=1,2,3, \ldots 10
$$

Second, the places of each $\alpha$-cuts to deal with the side bc are calculated.

$$
y h_{i}=\left(\frac{1}{b-a}\right) *\left(x h_{i}-a\right) \text { and } \mathrm{i}=1,2,3, \ldots 10
$$

And also, $x h_{11}=b$ and $y h_{11}=1$ are assumed. Finally, the equivalent weight of the triangular fuzzy number of $\widetilde{A}$ is

$$
W_{\tilde{A}}=\sum_{i=1}^{10}\left(x h_{i}^{*} y h_{i}^{0.01}\right)+b
$$

By this method the weight of $\widetilde{B}$ is also calculated as $W_{\widetilde{B}}$. At end the ratio of $W_{\widetilde{B}}: W_{\widetilde{B}}$ are considered as the ratio of two fuzzy numbers 


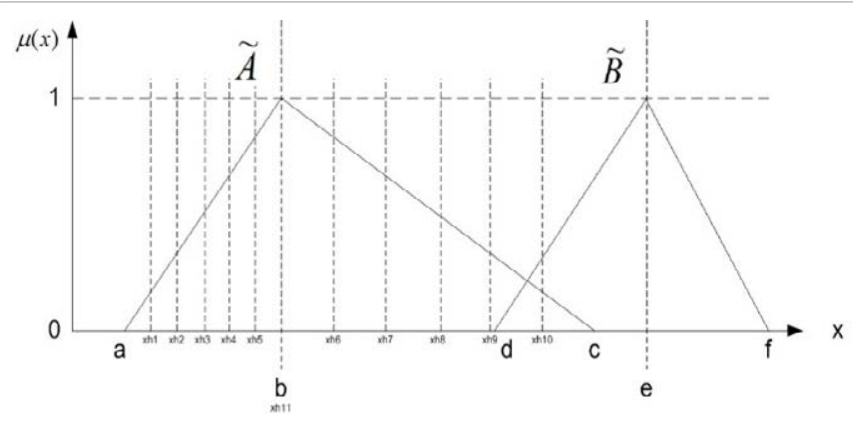

Figure 2: Comparing two triangular fuzzy number with no vertical side $(a \neq b \neq c)$.

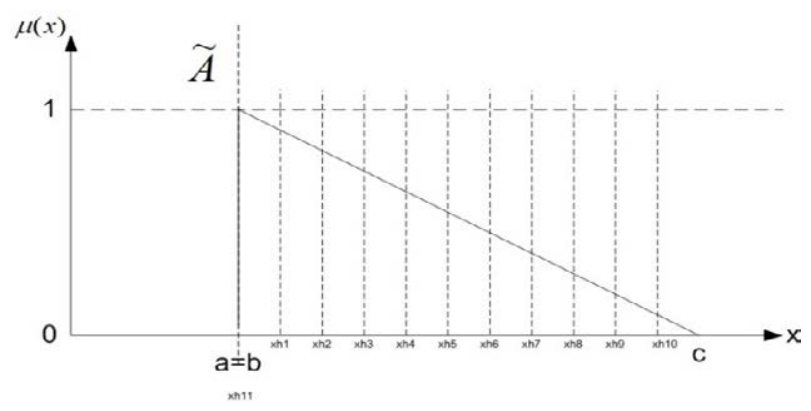

Figure 3: Triangular fuzzy number with a vertical side $(a=b, b \prec c)$.

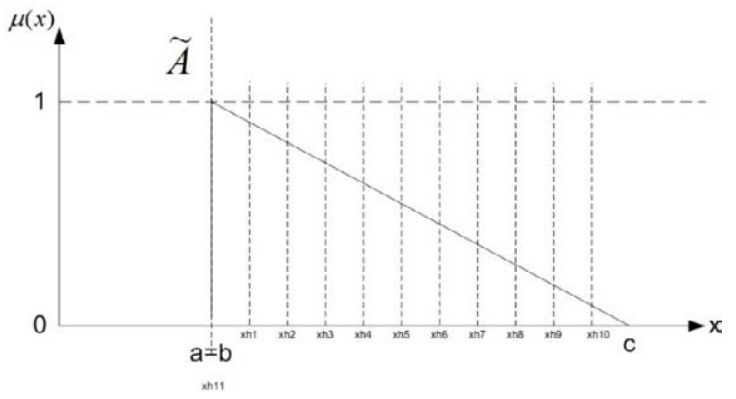

Figure 4: Triangular with a vertical side $(b=c, a \prec b)$.

of $\widetilde{A}: \widetilde{B}$.

It should be mentioned that although ten $\alpha$-cuts are conducted here but using more $\alpha$-cuts leads to more accuracy in calculating the equivalent crisp amount of a fuzzy number. Moreover, both vertical and horizontal characteristics of a fuzzy number should be used together. However, the horizontal intensity have to be more than the verticals which is the reason of the 0.01 power of $y h_{i}$ in calculating the $W_{\widetilde{A}}$ or $W_{\widetilde{B}}$. The power of 0.01 is gained due to the many trial and error calculations which led to the highest accuracy (Figure 5).

\section{Fuzzy RIAM method}

The rapid impact assessment matrix (RIAM) is a new tool for execution of an environmental impact assessment [17]. In this study, we used RIAM method [18] in order to evaluate environmental impacts of petrochemical industry (Figure 6). This study is an assessment procedure consists of three steps:

To hold a discussion meeting with experts to determine the effects on environmental factors using initial checklist,
To determine the components of the rapid matrix including a and $b$ groups of criteria,

\section{To evaluate using this matrix.}

On this basis this matrix was composed of columns, which include physical-chemical (PC), biological-ecological (BE), cultural-social (CS) and economic- operational (EO) part in the first column. The most important detailed activities are described in Table 1.

In the next step, the effects of project activities on environmental components were scored using defined criteria. However, evaluation criteria were divided into two groups based on the RIAM method: 1.Criteria that are more important and individually can change the scores (group A consisting of criteria a1 and a2); 2. Criteria of relative importance that are not able to change scores individually (group B consisting of criteria b1, b2 and b3) (Figure 7).

In this scoring system, scores corresponding to first group are multiplied by each other, thus; these criteria will weigh more in scoring and as the scores of the second group are summed together they will weight lower but they are considered in scoring yet. Both scores are multiplied together to determine the final environmental assessment score or ES. The scoring formula is as follow [18]:

$$
\begin{aligned}
& (\mathrm{a} 1)^{\star}(\mathrm{a} 2)=\mathrm{aT} \\
& (\mathrm{b} 1)+(\mathrm{b} 2)+(\mathrm{b} 3)=\mathrm{bT} \\
& (\mathrm{aT}){ }^{\star}(\mathrm{bT})=\mathrm{ES}
\end{aligned}
$$

In first group criteria a1 and a2 indicate the importance and magnitude criterion of the impact respectively. In second Group criteria $\mathrm{b} 1, \mathrm{~b} 2, \mathrm{~b} 3$, respectively, indicate the permanent reversibility and cumulative criterion (Table 2). Obviously, it should be initially determined if the effect is positive or negative and then the scoring would be done.

In order to analyze results of the scoring in this method, resulting environmental scores (ES) should be investigated in Table 3 range bands. Therefore range bands of positive and negative impacts for each component of the environment should initially be determined $[19,20]$. Finally we can select the option that has the least negative impact.

The main operators in fuzzy environment:

$$
\begin{aligned}
& \mathrm{A}=(\mathrm{a} 1, \mathrm{~b} 1, \mathrm{c} 1) \\
& \mathrm{B}=(\mathrm{a} 2, \mathrm{~b} 2, \mathrm{c} 2)
\end{aligned}
$$$$
\mathrm{A}+\mathrm{B}=(\mathrm{a} 1+\mathrm{a} 2, \mathrm{~b} 1+\mathrm{b} 2, \mathrm{c} 1+\mathrm{c} 2)
$$

If both are positive:

$\mathrm{A}^{\star} \mathrm{B}=\left(\mathrm{a} 1^{\star} \mathrm{a} 2, \mathrm{~b} 1^{*} \mathrm{~b} 2, \mathrm{cl}{ }^{*} \mathrm{c} 2\right)$

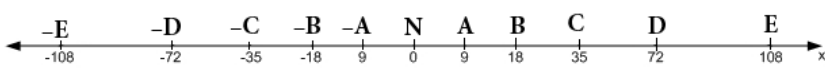

Figure 5: RB in Classical method.

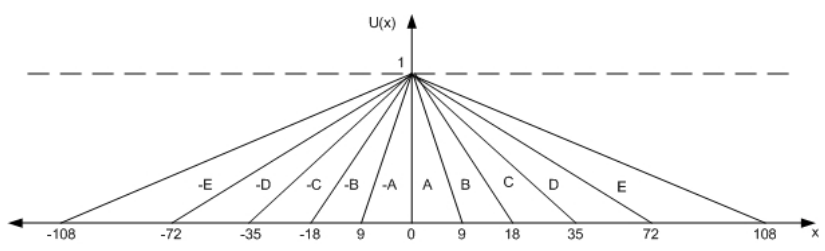

Figure 6: RB in fuzzy method. 
Citation: Ghobadi M, Jafari HR, Bidhendi GRN, Yavari AR (2015) Environmental Impact Assessment of Petrochemical Industry using Fuzzy Rapid Impact Assessment Matrix. J Pet Environ Biotechnol 6: 247. doi:10.4172/2157-7463.1000247

Page 4 of 7

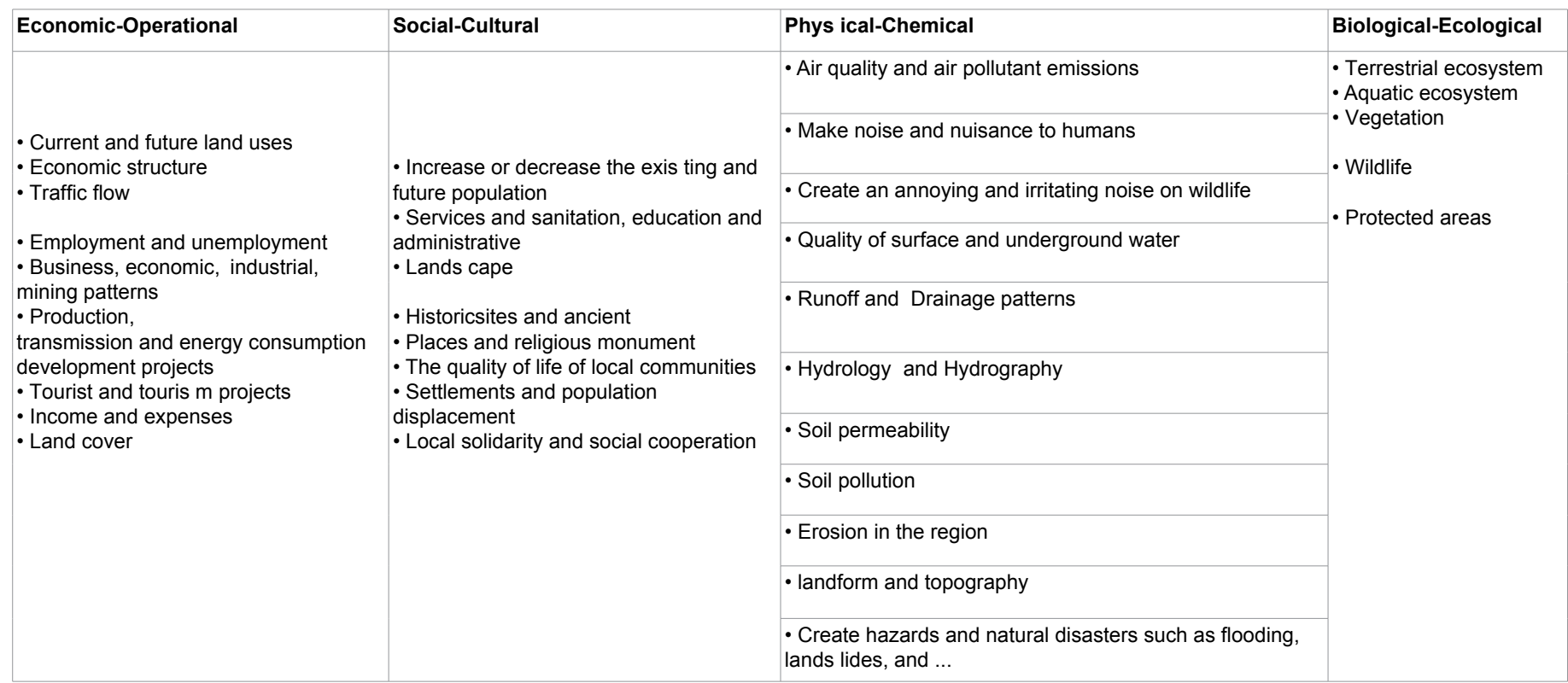

Table 1: Indexes of environmental impact assessment for petrochemical industy.

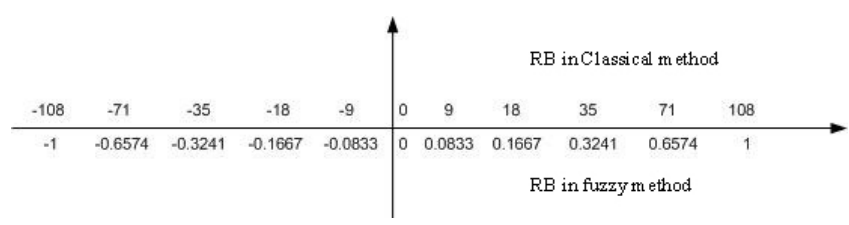

Figure 7: RB values in both classical and fuzzy.

\begin{tabular}{|c|c|c|c|c|}
\hline \multicolumn{2}{|l|}{ Criteria } & \multirow{2}{*}{$\begin{array}{l}\text { Scale } \\
4\end{array}$} & \multirow{2}{*}{$\begin{array}{l}\text { Fuzzy Scale } \\
(3,4,5)\end{array}$} & \multirow{2}{*}{$\begin{array}{l}\text { Description } \\
\text { Important to national/international } \\
\text { interes t }\end{array}$} \\
\hline \multirow{12}{*}{$\begin{array}{l}\text { (A) } \\
\text { Criteria }\end{array}$} & \multirow{5}{*}{$\begin{array}{l}\text { A1: } \\
\text { Importance } \\
\text { of condition }\end{array}$} & & & \\
\hline & & 3 & $(2,3,4)$ & $\begin{array}{l}\text { Important to regional/national } \\
\text { interes ts }\end{array}$ \\
\hline & & 2 & $(1,2,3)$ & $\begin{array}{l}\text { Important to areas immediately } \\
\text { outs ide the local } \\
\text { condition }\end{array}$ \\
\hline & & 1 & $(0,1,2)$ & Important only to the local condition \\
\hline & & 0 & $(0,0,0)$ & No importance \\
\hline & \multirow{6}{*}{$\begin{array}{l}\text { A2: } \\
\text { Magnitude of } \\
\text { change/ } \\
\text { effect }\end{array}$} & 3 & $(2,3,4)$ & Major positive benefit \\
\hline & & 2 & $(1,2,3)$ & $\begin{array}{l}\text { Significant improvement in status } \\
\text { quo }\end{array}$ \\
\hline & & 1 & $(0,1,2)$ & Improvement in status quo \\
\hline & & 0 & $(0,0,0)$ & No change/status quo \\
\hline & & -1 & $(-2,-1,0)$ & Negative change in status quo \\
\hline & & -2 & $(-3,-2,-1)$ & $\begin{array}{l}\text { Significant negative disbenefit or } \\
\text { change }\end{array}$ \\
\hline & & -3 & $(-4,-3,-2)$ & Major disbenefit or change \\
\hline \multirow{9}{*}{$\begin{array}{l}(\mathrm{B}) \\
\text { Criteria }\end{array}$} & \multirow{3}{*}{$\begin{array}{l}\text { B1: } \\
\text { Permanence }\end{array}$} & 1 & $(0,1,2)$ & No change/not applicable \\
\hline & & 2 & $(1,2,3)$ & Temporary \\
\hline & & 3 & $(2,3,4)$ & Permanent \\
\hline & \multirow{3}{*}{$\begin{array}{l}\text { B2: } \\
\text { Reversibility }\end{array}$} & 1 & $(0,1,2)$ & No change/not applicable \\
\hline & & 2 & $(1,2,3)$ & Reversible \\
\hline & & 3 & $(2,3,4)$ & Irreversible \\
\hline & \multirow{3}{*}{$\begin{array}{l}\text { B3: } \\
\text { Cumulative }\end{array}$} & 1 & $(0,1,2)$ & No change/not applicable \\
\hline & & 2 & $(1,2,3)$ & Non-cumulative/single \\
\hline & & 3 & $(2,3,4)$ & Cumulative/synergistic \\
\hline
\end{tabular}

Table 2: Fuzzy RIAM method assessment criteria.
If one is negative:

$\mathrm{A}^{\star} \mathrm{B}=\left(\mathrm{a} 1^{\star} \mathrm{c} 2, \mathrm{~b} 1^{\star} \mathrm{b} 2, \mathrm{a} 2^{\star} \mathrm{c} 1\right)$

\section{Results}

In this study, the fuzzy RIAM method were used to assess the environmental impacts of petrochemical industry on the environmental factors, implementing intended included 4 major factors and 33 subfactors, and after implementation of the method used was prepared in the MATLAB software, the results in the form of tables and graphs for options of non-implementation, construction and operation stage, which the results are discussed below.

As can be seen in the Table 4 and Figure 8 related to the lack of implementation option, forecast and analysis of the works indicates that the main consequences of the lack of implementation of petrochemical project in the study include the following:

In the physical-chemical, and biological-ecological parts, almost lack of implementation of the project won't change the environment, while the lack of implementation of the project for social-cultural and economic-functional parts will have significant negative impacts, so that the lack of implementation of projects in the social-cultural part will have the most negative impact on congestion, increase or decrease in population, services and sanitation, education and administration, quality of life for local communities, displacement of settlements and local population and social cooperation. It is better that the project is on the agenda with the adoption of corrective procedures to improve the environment to reduce the effects of project activities on environmental factors. In connection with the economic-functional parts, impact assessment shows that the project activities have significant negative impacts on current and future land use, economic structures, traffic flow, employment and unemployment, trade \& economic patterns, production development projects, transport and energy costs, tourist projects and tourism, income and expenses and land cover and severe have major negative impacts, and it is suggested to prevent the lack of implementation of the project in order to reduce these negative effects.

As can be seen in the Table 5 and Figure 9 related to evaluate the effects of construction activities in the petrochemical industry, 
Citation: Ghobadi M, Jafari HR, Bidhendi GRN, Yavari AR (2015) Environmental Impact Assessment of Petrochemical Industry using Fuzzy Rapid Impact Assessment Matrix. J Pet Environ Biotechnol 6: 247. doi:10.4172/2157-7463.1000247

Page 5 of 7

\begin{tabular}{|l|l|l|l|}
\hline Description & ES & Fuzzy ES & ES s ' compare to the (0,0,108) or (-108,0,0) \\
\hline Major positive change/impacts & $72+$ to $108+$ & $(0,0,108)$ & 1 \\
\hline Significant positive change/impacts & $36+$ to $71+$ & $(0,0,71)$ & 0.6574 \\
\hline Moderately positive change/impacts & $19+$ to $35+$ & $(0,0,35)$ & 0.3241 \\
\hline Pos itive change/impacts & $10+$ to $18+$ & $(0,0,18)$ & 0.1667 \\
\hline Slightly positive change/impacts & $1+$ to $9+$ & $(0,0,9)$ & 0.0833 \\
\hline No change/status quo/not applicable & zero & $(0,0,0)$ & 0 \\
\hline Slightly negative change/impacts & -1 to -9 & $(-9,0,0)$ & -0.0833 \\
\hline Negative change/impacts & -10 to -18 & $(-18,0,0)$ & -0.1667 \\
\hline Moderately negative change/impacts & -19 to -35 & $(-35,0,0)$ & -0.3241 \\
\hline Significant negative change/impacts & -36 to -71 & $(-71,0,0)$ & -0.6574 \\
\hline Major negative change/impacts & -72 to -108 & $(-108,0,0)$ & -1 \\
\hline
\end{tabular}

Table 3: Conversion of environmental scores to range bands $[13,14]$.

\begin{tabular}{|c|c|c|c|c|c|c|c|c|c|c|c|}
\hline $\mathbf{R B}$ & $\mathbf{+ E}$ & $\mathbf{+ D}$ & $\mathbf{+ C}$ & $\mathbf{+ B}$ & $\mathbf{+ A}$ & $\mathbf{N}$ & $\mathbf{- A}$ & $\mathbf{- B}$ & $\mathbf{- C}$ & $\mathbf{- D}$ & $\mathbf{- E}$ \\
\hline PC & 0 & 0 & 0 & 0 & 0 & 11 & 0 & 0 & 0 & 0 & 0 \\
\hline BE & 0 & 0 & 0 & 0 & 0 & 5 & 0 & 0 & 0 & 0 & 0 \\
\hline SC & 0 & 0 & 0 & 0 & 0 & 3 & 1 & 0 & 1 & 3 & 0 \\
\hline EO & 0 & 0 & 0 & 0 & 0 & 2 & 1 & 1 & 0 & 2 & 3 \\
\hline Sum & 0 & 0 & 0 & 0 & 0 & 21 & 2 & 1 & 1 & 5 & 3 \\
\hline
\end{tabular}

Table 4: The number and range of effects for non-implementation.

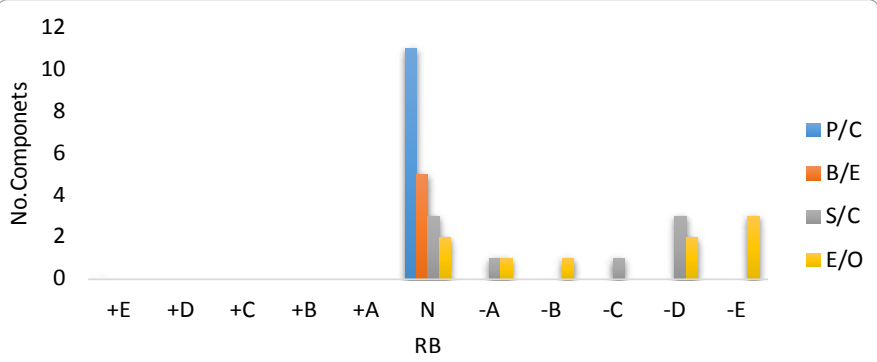

Figure 8: The number and range of effects for non-implementation.

\begin{tabular}{|c|c|c|c|c|c|c|c|c|c|c|c|}
\hline RB & $+\mathbf{+ E}$ & $\mathbf{+ D}$ & $\mathbf{+ C}$ & $\mathbf{+ B}$ & $\mathbf{+ A}$ & $\mathbf{N}$ & $\mathbf{- A}$ & $\mathbf{- B}$ & $\mathbf{- C}$ & $\mathbf{- D}$ & $\mathbf{- E}$ \\
\hline PC & 0 & 0 & 0 & 0 & 0 & 0 & 3 & 2 & 3 & 1 & 2 \\
\hline BE & 0 & 0 & 0 & 0 & 0 & 0 & 0 & 0 & 3 & 1 & 1 \\
\hline SC & 0 & 0 & 1 & 3 & 1 & 0 & 2 & 0 & 0 & 1 & 0 \\
\hline EO & 0 & 2 & 3 & 2 & 1 & 0 & 0 & 0 & 0 & 1 & 0 \\
\hline Sum & 0 & 2 & 4 & 5 & 2 & 0 & 5 & 2 & 6 & 4 & 3 \\
\hline
\end{tabular}

Table 5: The number and range of effects for Construction stage.

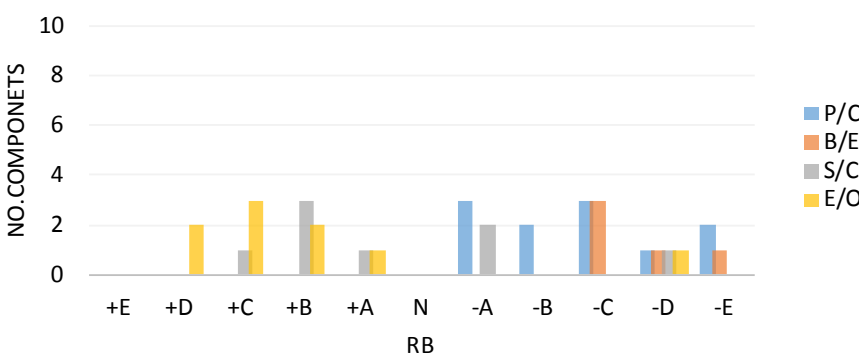

Figure 9: The number and range of effects for Construction stage.

forecasts and analysis of the works indicates that the main works of construction stage in the petrochemical industry in the study area include the following:

In the physical-chemical part, there are major and significant negative impacts, and major negative impacts are related to create noise and nuisance to humans and wildlife of the area, and it has significant negative impacts on erosion in the area and terrain and topography, and it can cause the risk of natural disasters such as flooding and exacerbate, landslides, landslides and so on. Therefore, it is suggested that, at the of construction, to reduce nuisance and harassment noise, corrective measures to be taken to control noise and vibration, and to mitigate the negative impacts on the land form and intensification of risks and accidents, it is suggested to take the necessary measures by anticipation the type of hazards and their risk assessment.

In the biological-ecological part, the most significant negative impacts is related to wildlife and vegetation, In the next step, the negative impacts are related to land and water ecosystems and protected areas. Various activities in the construction stage of the project, such as transport, labor activity and other activities, all of them lead to ecological imbalance and disturbance and damage to fauna and flora of the region. For social-cultural part, the construction stage of project only have negative effects on the landscape, historic sites and ancient places, and but it should be noted that these impacts are not very significant and negative, by contrast, they will have little positive impact on social-cultural part. In the economic-functional part, impact assessment shows that the construction stage of the petrochemical industry has only significant negative impact on traffic flow, which must be managed by corrective measures. Almost at the end of project, the project activities has positive and helpful impacts on other economic-functional factors, and it has the most positive effects on the employment and improve the income of residents.

As can be seen in the Table 6 and Figure 10 to assess the environmental effects of the operation stage of the petrochemical industry, forecasts and analysis of the works indicates that the main works of the operation stage in the petrochemical industry in the study area include the following:

In the physical-chemical part, it has major negative impacts on noise, soil, air and water pollution and the quality of resources, which using monitoring programs, constantly and frequently, the amount of emissions from industrial activities should be considered, it also has significant negative impacts on other factors of this part.

For biological-ecological part, aquatic ecosystems and the fauna and flora of the region are affected by the major negative impacts of industrial activities, and for terrestrial ecosystems and protected areas also significant negative impacts can be predicted, therefore, it is recommended that location of petrochemical industry has great distance with water ecosystems, and to mitigate the effects on the fauna of the area, uncover places or places that are devoid of vegetation should be selected for development of the petrochemical industry. 


\begin{tabular}{|c|c|c|c|c|c|c|c|c|c|c|c|}
\hline RB & +E & +D & +C & +B & +A & N & -A & -B & -C & -D & -E \\
\hline PC & 0 & 0 & 0 & 0 & 0 & 0 & 1 & 0 & 1 & 5 & 4 \\
\hline BE & 0 & 0 & 0 & 0 & 0 & 0 & 0 & 0 & 0 & 2 & 3 \\
\hline SC & 3 & 1 & 1 & 0 & 0 & 0 & 0 & 3 & 0 & 0 & 0 \\
\hline EO & 5 & 2 & 1 & 1 & 0 & 0 & 0 & 0 & 0 & 0 & 0 \\
\hline Sum & 8 & 3 & 2 & 1 & 0 & 0 & 1 & 3 & 1 & 7 & 7 \\
\hline
\end{tabular}

Table 6: The number and range of effects for Operation.

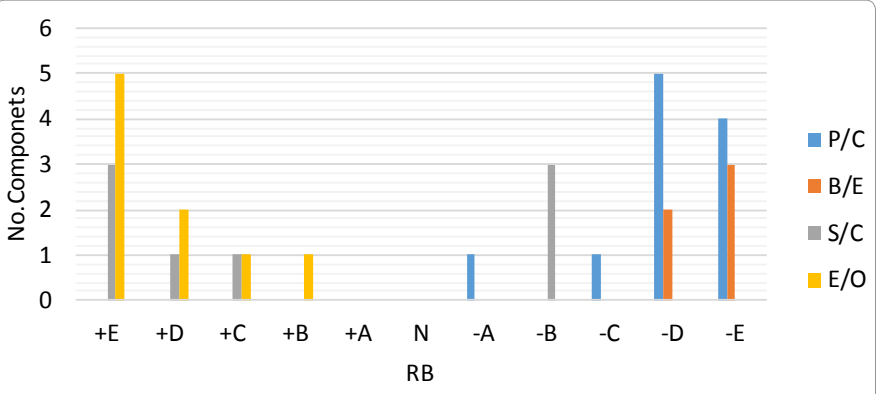

Figure 10: The number and range of effects for Operation.

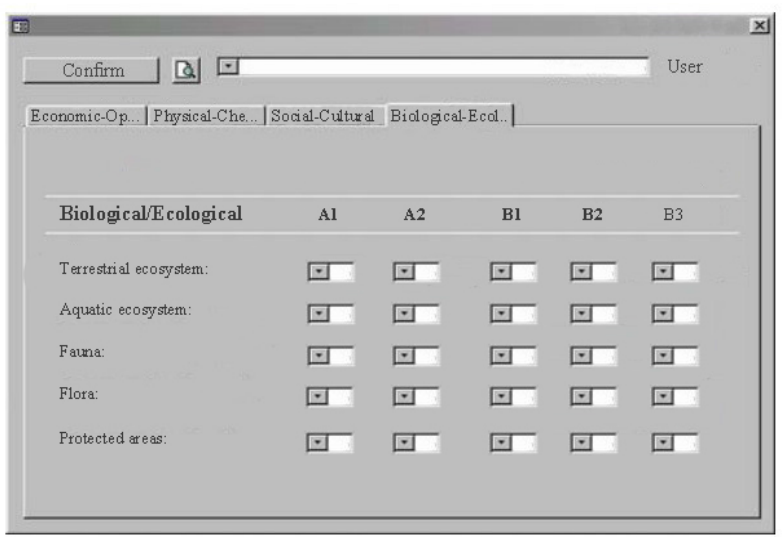

Figure 11: Decision support system designed to fuzzy RIAM method.

For social-cultural parts, the slightly negative impacts on landscape, historic sites and archaeological and religious sites, and the monument can be seen, and the significant positive impacts can be seen on density, increase or decrease in population, services and sanitation, education and administration, the quality of life of local communities, settlements and population displacement and local solidarity and social cooperation. In connection with the economic-functional part, impact assessment shows that the project activities have significant positive and major positive impacts on current and future land use, economic fundamentals, jobs and unemployment, trade \& economic patterns, production development projects, transfer and energy costs, tourist projects and tourism, income and expenses and land cover and, and the only negative impact of the operation is related to the traffic.

A picture of a system designed to assess by using the fuzzy RIAM method is presented in the following (Figure 11).

\section{Conclusion}

The study of development projects of petrochemical industry shows that, in the past planning, like many developing countries, the importance and values of natural resources and the environment has been hidden from the perspective of decision-makers, and many of them have designed and operated without regard to environmental considerations. The results and consequences of such measures have been the incidence of severe pollution and degradation of environmental resources. Certainly, petrochemical plants can also be considered as plans and development projects which have the short and long-term environmental effects. The results show that the most significant environmental and exploitation impacts of petrochemical projects are water and soil pollution, air and noise, as well as socioeconomic consequences. Petrochemical industries in the operation will create more significant implications than the construction stage on the environment, some of them in terms of lack of control and environmental management, are irreversible and damaging. The most important environmental effects of the construction stage of petrochemical industries include changes in land use, increased noise, disruption in transportation patterns, weather and air pollution and waste production. The adverse effects of the operation stage of the petrochemical industry include water pollution of acceptor sources, air pollution, solid waste and hazardous wastes. Basically, the major environmental problems of these plants, especially in terms of noncompliance with environmental regulations and standards have risky consequences, and impair the organic nature of human societies and also wildlife. However, it can be said that, consequences and effects of the activities of petrochemical projects, in the both of construction and operation stages are different and they have obvious differences in intensity and scope and importance. Thus, to evaluate petrochemical projects, like other similar projects, several effects must be studied, analyzed and dissected. It is also recommended that, to reduce the negative impact of environmental factors on the development of the petrochemical industry, both remedial and mitigation plans used. It is also recommended that both corrective measures and improvement programs are used to reduce the negative impacts of the development of petrochemical industry on the environmental factors.

\section{References}

1. Muro M, Jeffrey P (2008) A critical review of the theory and application of social learning in articipatory natural resource management processes. Journal of environmental planning and management 51: 325-344.

2. Samuel VB, Agamuthu P, Hashim MA (2013) Indicators for assessment of sustainable production: A case study of the petrochemical industry in Malaysia. Ecological Indicators 24: 392-402.

3. Singh RK, Murty HR, Gupta SK, Dikshit AK (2012) An overview of sustainability assessment methodologies. Ecological Indicators 15: 281-299.

4. Carvalho A, Mimoso AF, Mendes AN, Matos HA (2014) From a literature review to a framework for environmental process impact assessment index. Journal of Cleaner Production 64: 36-62.

5. Hoogstra-Klein, MA, Permadi DB, Yasmi Y (2012) The value of cultural theory for participatory processes in natural resource management. Forest Policy and Economics 20: 99-106.

6. Cole RJ (2005) Building environmental assessment methods: redefining intentions and roles. Building Research \& Information 33: 455-467.

7. Glasson J, Therivel R, Chadwick A (2013) Introduction to environmental impact assessment. Routledge, Oxford University Press, London.

8. Hanna KS (2009) Environmental impact assessment: practice and participation Oxford University Press, USA.

9. Rezaie NM, Ezlin NAB, Othman J (2010) Knowledge-based system for environmental impact assessment application to oil refinery plant in Iran a case study. Tehran oil refinery.

10. Narimisa MR, Rezaei M, Kamaei H, Zangeneh FK (2013) Modeling for Environmental Impact Assessment of oil refineries in Iran. Life Science Journal 10: $7 \mathrm{~s}$.

11. Bhatt RP, Khanal SN (2010) Environmental impact assessment system and process: A study on policy and legal instruments in Nepal. African Journal of Environmental Science and Technology 4: 586-594. 
Citation: Ghobadi M, Jafari HR, Bidhendi GRN, Yavari AR (2015) Environmental Impact Assessment of Petrochemical Industry using Fuzzy Rapid Impact Assessment Matrix. J Pet Environ Biotechnol 6: 247. doi:10.4172/2157-7463.1000247

12. Pandey SK (2015) Environmental impact assessment and environmental management studies for synthetic organic chemicals. International Journal 3: 60-76.

13. Klir G, Yuan B (1995) Fuzzy sets and fuzzy logic. New Jersey. Prentice Hall 4.

14. Zhu X, Zhang L, Ran R, Mol AP (2015) Regional restrictions on environmental impact assessment approval in China: the legitimacy of environmental authoritarianism. Journal of Cleaner Production 92: 100-108.

15. Lee KH (2006) First course on fuzzy theory and applications. Springer Science \& Business Media 27.

16. Zimmermann HJ (2010) Fuzzy set theory. Wiley Interdisciplinary Reviews: Computational Statistics 2: 317-332.
17. Suthar S, Sajwan A (2014) Rapid impact assessment matrix (RIAM) analysis as decision tool to select new site for municipal solid waste disposal: A case study of Dehradun city, India. Sustainable Cities and Society 13: 12-19.

18. Pastakia CM, Jensen A (1998) The rapid impact assessment matrix (RIAM) for EIA. Environmental Impact Assessment Review 18: 461-482.

19. Pradhan N, Habib H, Venkatappa M, Ebbers T, Duboz R, et al. (2015) Framework tool for a rapid cumulative effects assessment: case of a prominent wetland in Myanmar. Environmental monitoring and assessment 187: 1-18.

20. Yuan K, Zhang J, Meng F, Xiao Y, Zhang Y (2012) Application of Noise System Model in Environmental Impact Assessment of Petrochemical Industry. Environmental Science and Management 37: 179-182. 